\section{RMD Open}

Rheumatic \&

Musculoskeletal Diseases

\title{
Development of classification criteria for hand osteoarthritis: comparative analyses of persons with and without hand osteoarthritis
}

To cite: Haugen IK, Felson DT, Abhishek A, et al. Development of classification criteria for hand osteoarthritis: comparative analyses of persons with and without hand osteoarthritis. RMD Open 2020;6: 0001265 . doi:10.1136/rmdopen-2020001265

- Additional material is published online only. To view please visit the journal online (http://dx.doi.org/10.1136/rmdo pen-2020-001265)

Received 10 April 2020 Revised 26 May 2020 Accepted 31 May 2020
Check for updates

(C) Author(s) (or their employer(s)) 2020. Re-use permitted under CC BY-NC. No commercial re-use. See rights and permissions. Published by BMJ.

For numbered affiliations see end of article.

Correspondence to Ida K Haugen; ida.haugen@diakonsyk.no

\section{ABSTRACT}

Objectives Further knowledge about typical hand osteoarthritis $(O A)$ characteristics is needed for the development of new classification criteria for hand $\mathrm{OA}$. Methods In a cross-sectional multi-centre international study, a convenience sample of patients from primary and secondary/tertiary care with a physician-based hand $\mathrm{OA}$ diagnosis $(n=128)$ were compared with controls with hand complaints due to inflammatory or non-inflammatory conditions $(n=70)$. We examined whether self-reported, clinical, radiographic and laboratory findings were associated with hand $\mathrm{OA}$ using logistic regression analyses.

Discrimination between groups was assessed by calculating the area under receiver operating curves (AUC).

Results Strong associations with hand $\mathrm{OA}$ were observed for radiographic osteophytes $(\mathrm{OR}=1.62,95 \% \mathrm{Cl} 1.40$ to 1.88$)$ and joint space narrowing (JSN) (OR $=1.57,95 \% \mathrm{Cl} 1.36$ to 1.82) in the distal interphalangeal (DIP) joints with excellent discrimination (AUC $=0.82$ for both). For osteophytes and JSN we found acceptable discrimination between groups in the proximal interphalangeal joints (AUC $=0.77$ and 0.78 , respectively), but poorer discrimination in the first carpometacarpal joints (AUC $=0.67$ and 0.63 , respectively). Painful DIP joints were associated with hand $\mathrm{OA}$, but were less able to discriminate between groups (AUC $=0.67$ ). Age and family history of $O A$ were positively associated with hand $O A$, whereas negative associations were found for pain, stiffness and soft tissue swelling in metacarpophalangeal joints, pain and marginal erosions in wrists, longer morning stiffness, inflammatory biomarkers and autoantibodies.

Conclusions Differences in symptoms, clinical findings, radiographic changes and laboratory tests were found in patients with hand $O A$ versus controls. Radiographic $O A$ features, especially in DIP joints, were best suited to discriminate between groups.

\section{INTRODUCTION}

Hand osteoarthritis (OA) is currently being classified by the 1990 American College of

\section{Key messages}

What is already known about this study?

- Current hand OA classification criteria are unable to classify persons with hand $\mathrm{OA}$ based on radiographic findings, and they are hampered by being insensitive to classify hand $\mathrm{OA}$ in the general population.

What does this study add?

- Our study shows that radiographic findings, especially in the DIP joints, demonstrate better discrimination between hand $\mathrm{OA}$ and controls than features by clinical examination.

- Among self-reported symptoms, best discrimination between hand $\mathrm{OA}$ and controls was found for pain on most days the previous 6 weeks in the DIP joints.

How might this impact on clinical practice?

- Identification of typical hand OA features is needed before new classification criteria can be developed and tested in decision analytic software.

- Widespread use of new classification criteria will enable comparisons of disease prevalent and incidence across observational studies and testing of treatments in clinical trials.

Rheumatology (ACR) criteria, ${ }^{1}$ which have important shortcomings that might prevent much-needed insight in hand OA pathogenesis and testing of treatments in clinical trials. Importantly, the criteria are based on clinical examination parameters often with poor reliability without the possibility to classify hand OA based on radiographs. Moreover, they define OA as present almost exclusively based on a combination of affected joints in the 2nd and 3rd 
fingers and the thumb base. Since the control group in the development of the criteria mainly consisted of persons with rheumatoid arthritis (RA), the criteria are not well suited to classify hand OA in a wider population with rheumatic and musculoskeletal diseases (RMDs). Mainly severe hand OA will be classified by the ACR criteria making them insensitive in the general population. Lastly, all hand OA phenotypes are lumped together, without taking into consideration that different phenotypes could have different pathogenesis or treatment.

Research on the natural disease course and development of effective treatment options is seriously hampered by the lack of good classification criteria. For example, comparisons of disease incidence and prevalence are difficult. Since different definitions of hand OA are used in clinical trials rather than the ACR criteria, it is challenging to perform systematic reviews or meta-analyses. ${ }^{2}$ Members of the EULAR taskforce for evidence-based recommendations on hand OA diagnosis ranked the development of new classification criteria as a top research priority. ${ }^{3}$

Our aim is to identify features that are associated with hand $\mathrm{OA}$ and that can discriminate hand $\mathrm{OA}$ and controls in a population with hand complaints as a first step to develop new classification criteria for hand OA overall and different hand OA phenotypes.

\section{METHODS}

\section{Study design}

We collected data on patients with hand complaints from Europe and North America. Patients were recruited from primary (2 centres) and secondary/tertiary care (10 centres). Physicians recruited patients with hand complaints, which could be due to either hand OA (ranging from mild to severe) or inflammatory and non-inflammatory non-traumatic conditions. Strict numbers of patients within each category were not provided. Patients with unclear causes of their hand complaints were also included. The treating physician made the diagnosis. We aimed for approximately 200 patients in our data set, a number targeted in previous classification criteria efforts. ${ }^{4}$ The data collection was funded by the EULAR.

\section{Hand questionnaires}

All patients responded to questions about hand complaints, including symptom duration and duration of morning stiffness in fingers and thumb base joints. On four separate hand diagrams, they marked the hand joints (bilateral 2nd-5th distal interphalangeal (DIP), 1st-5th proximal interphalangeal (PIP), 1st-5th metacarpophalangeal (MCP) and thumb base) that had been painful and stiff during the last 48 hours and on most days the previous 6 weeks. On a whole-body homunculus, they marked the joints (bilateral shoulders, elbows, wrists, hips, knees, ankles and toes) and spine (neck, upper, middle and lower back) that had been painful on most days the previous 6 weeks. All toes in one foot were regarded as one entity. Surgically modified joints were marked on the same diagram. They completed the Australian/Canadian hand index pain (range 0-20), stiffness (range 0-4) and function subscales (range 0-36) and the Functional Index of Hand OA (range 0-30). ${ }^{5} 6$

The patients self-reported painful locking of fingers, numbness and tingling in the hands, current/past psoriasis, current/past inflammatory bowel disease, and family history of OA, bony swellings/nodes and psoriasis in first-degree relatives.

\section{Clinical examination}

A physician or nurse examined all hand joints (bilateral 2nd-5th DIP, 1st-5th PIP, 1st-5th MCP and thumb base) for absence/presence of bony enlargement, pain on pressure and soft tissue swelling. Malalignment was assessed in the DIP, PIP $\left(>15^{\circ}\right)$ and the thumb base joints (squaring). Absence/presence of dactylitis (2nd-5th fingers) and tenosynovitis (2nd-5th fingers and thumb base) were evaluated bilaterally. On the body homunculus, pain on pressure (upper and middle back, bilateral shoulders, elbows, wrists, knees and feet) or movement (neck, lower back, bilateral hips and ankles) was marked. Body weight and height were self-reported or measured. The study personnel had previous experience in joint examination, but no formal training was performed prior to the data collection. No reliability data was available.

For each patient recruited into the study, the physicians were asked: 'How likely is it that the hand complaints in this patient are due to hand OA' on a $0-10$ scale $(0=$ 'not likely', $10=$ 'very likely'). For scores $0-7$, the physician indicated the cause of complaints on a list with 16 RMDs other than hand OA (response alternatives: 'no', 'unclear', 'yes').

\section{Hand radiographs}

Bilateral hand radiographs obtained at each centre were de-identified and read centrally by two trained readers (IKH, FK). The central readers have demonstrated excellent inter-reader reliability in a previous clinical trial. ${ }^{7}$ Bilateral 2nd-5th DIP, 1st-5th PIP, 1st-5th MCP, 1st carpometacarpal (CMC1) and scaphotrapeziotrapezoid (STT) joints were read according to a modified KellgrenLawrence scale (grade 0-4). ${ }^{8}$ All joints were read for osteophytes (grade 0-3) and joint space narrowing (JSN, grade $0-3$ ), and the DIP and PIP joints were also read for central erosions. ${ }^{9}$ The readers counted the number of joints within three joint groups (PIP, MCP and wrist) with marginal erosions. ${ }^{10}$

A trained rheumatologist (MK) adjudicated the scoring of osteophytes and JSN in joints where one central reader scored no pathology and the other central reader scored grade 2-3. Central erosions were adjudicated by MK when the number of DIP or PIP joints with erosions differed by 2 or more. A trained rheumatologist $(\mathrm{DvdH})$ adjudicated the scoring of marginal erosions if the number of marginal erosions in the PIP, MCP or wrist joint groups differed by 2 or more between the central readers. 
We used the average score of the central readers (FK, IKH), except from cases of adjudication, where the adjudicated scores (MK or DvdH) were used.

\section{Laboratory tests}

Due to feasibility and costs, blood tests were analysed at local laboratories for erythrocyte sedimentation rate (ESR), Creactive protein (CRP), anti-cyclic citrullinated peptide (anti-CCP) and rheumatoid factor (RF) if considered relevant as part of the clinical routine. ESR and CRP could not be treated as continuous variables since the lowest possible measurement differed across laboratories. The values were dichotomised (ESR $\geq 15 \mathrm{~mm} /$ hour and $\mathrm{CRP} \geq 5 \mathrm{mg} / \mathrm{L}$, respectively) based on the highest observed area under receiver operating curves (AUC) for different cut-off values in our study population. Due to different cut-off values for elevated anti-CCP and RF across laboratories, the autoantibodies were dichotomised based on the provided reference value for each laboratory.

\section{Patient and public involvement}

Two European patient research partners (EG and WS) were involved in the development of the protocol and the preparations of this manuscript and will also be involved in the future steps of the development of the classification criteria sets.

\section{Statistical analyses}

Based on the question 'How likely is it that the hand complaints in this patient are due to hand OA', we divided the patients into three groups: clearly not OA (score 0-3, 'control group'), unclear (score 4-6) and clearly OA (score 7-10, 'hand OA group'). The control and hand OA groups were included in further analyses, whereas the unclear group was excluded from all analyses. We performed a series of logistic regression analyses using hand OA versus controls as the outcome, and selfreported, clinical and imaging data as explanatory variables. Analyses were done with exclusion of missing observations for the respective variable (available case analyses). Receiver operating curves were constructed and AUC was calculated. We defined AUC values of $0.50-0.59,0.60-0.69,0.70-0.79$ and $\geq 0.80$ as none, poor, acceptable and excellent discrimination, respectively. Statistical analyses were performed using IBM SPSS version 25 . Pvalues $<0.05$ were considered statistically significant.

\section{Ethical considerations}

Ethical committees in each participating country approved the study. Each patient received written and oral information about the study and gave their written informed consent prior to study entry.

\section{RESULTS}

We recruited 224 patients, of whom $70(31.3 \%)$ and 128 $(57.1 \%)$ were in the control and hand OA groups, respectively. We excluded $26(11.6 \%)$ patients from analyses since it was unclear whether their complaints were due to hand OA or not. Most controls $(\mathrm{n}=65,92.9 \%)$ and patients with hand OA $(\mathrm{n}=123,96.1 \%)$ were recruited from secondary/tertiary care $(\mathrm{n}=8$ and $\mathrm{n}=10$ different centers, respectively). The remaining controls and patients with hand OA were recruited from two primary care centres. The hand OA group was older and included more women than the controls. In both groups, the majority had experienced symptoms in their finger joints for more than 6 months. Fewer patients had symptoms in their thumb base (table 1). Online supplementary tables 1-3 provide detailed information about other explanatory variables, including the number of missing variables. Patients in the control group demonstrated a wide range of RMDs (table 2).

Demographic/clinical variables and self-reported symptoms Female sex, age, family history of OA and bony enlargement were positively associated with hand $\mathrm{OA}$, with best discrimination between hand $\mathrm{OA}$ and controls for age and family history of OA (table 3). Despite psoriasis being negatively associated with hand OA, it could not discriminate between groups. No association with hand OA was found for family history of psoriasis or selfreported inflammatory bowel disease (data not shown).

Finger joint symptoms lasting more than 6 months were positively associated with hand $\mathrm{OA}$, using less than 6 weeks as reference. Since a symptom duration of 6 weeks to 6 months was not associated with hand OA, we dichotomised the variable into ' 6 months or less' versus 'more than 6 months' in subsequent analyses (table 3). No association with hand OA was found for symptom duration in the thumb base joints (data not shown).

Morning stiffness in the fingers of $\geq 1$ min was present in $88(68.8 \%)$ of patients with hand OA and $53(75.7 \%)$ of controls. Most patients with hand OA with morning stiffness reported that it lasted maximum $30 \min (\mathrm{n}=70$, $79.5 \%)$. The duration of the morning stiffness in fingers and thumb base joints was negatively associated with hand OA with better discrimination for the fingers. Positive and negative associations with hand OA were found for pain on most days the previous 6 weeks in DIP and MCP joints, respectively (table 3 ). Similar results were found for painful joints during the last 48 hours (although a weakened association in DIP joints) and stiff joints during the previous 48 hours and 6 weeks (data not shown).

An inverse association between numbness and hand $\mathrm{OA}$ was observed, although not statistically significant (table 3 ). We found no associations with hand OA for tingling or locking of fingers (data not shown). Self-reported pain in elbow(s), wrist(s) and toes on most days the previous 6 weeks was negatively associated with hand OA (table $3)$. No associations with hand OA were found for selfreported pain or self-reported prostheses of other joints (data not shown). 
Table 1 Clinical characteristics of the study population

\begin{tabular}{|c|c|c|}
\hline Hand OA group $(n=128)$ & $\begin{array}{l}\text { Control group } \\
(n=70)\end{array}$ & \\
\hline Age, mean (SD) years & $63.7(12.1)$ & $54.6(13.3)$ \\
\hline Sex, $\mathrm{n}(\%)$ women & $113(88.3)$ & $53(75.7)$ \\
\hline $\begin{array}{l}\text { Body mass index, median } \\
\left(\text { IQR) } \mathrm{kg} / \mathrm{m}^{2 *}\right.\end{array}$ & $\begin{array}{l}24.6 \\
(22.1-28.6)\end{array}$ & $\begin{array}{l}26.1 \\
(22.1-29.0)\end{array}$ \\
\hline \multicolumn{3}{|l|}{ AUSCAN $^{*}$} \\
\hline - Pain (range: 0-20) & $8(5-12)$ & $8(3-12)$ \\
\hline - Stiffness (range: 0-4) & $2(1-3)$ & $2(1-3)$ \\
\hline Physical function (range: 0-36) & $17(10-24)$ & $15(15-25)$ \\
\hline FIHOA (range: 0-30)* & $7(3-12)$ & $5(2-13)$ \\
\hline \multicolumn{3}{|l|}{ Symptom duration in fingers } \\
\hline No response/not applicable & $12(9.4)$ & $3(4.3)$ \\
\hline$><6$ weeks & $2(1.6)$ & $7(10.0)$ \\
\hline 6 weeks to 6 months & $6(4.7)$ & $7(10.0)$ \\
\hline$>6$ months & $108(84.4)$ & $53(75.7)$ \\
\hline \multicolumn{3}{|l|}{$\begin{array}{l}\text { Symptom duration in thumb } \\
\text { base }\end{array}$} \\
\hline No response/not applicable & $36(28.1)$ & $28(40.0)$ \\
\hline$><6$ weeks & $7(5.5)$ & $3(4.3)$ \\
\hline 6 weeks to 6 months & $6(4.7)$ & $5(7.1)$ \\
\hline$>>6$ months & $79(61.7)$ & $34(48.6)$ \\
\hline
\end{tabular}

*Missing information about body mass index $(n=1)$, FIHOA $(n=20)$ and AUSCAN $(n=7)$ in the hand OA group. Missing information about FIHOA $(n=9)$ and AUSCAN $(n=1)$ in the control group. AUSCAN, Australian/Canadian hand index; FIHOA, Function Index of Hand OA OA, osteoarthritis.

\section{Clinical examination features}

The greatest discrimination between hand OA and controls was mostly found for clinical features in the DIP joints (table 4). The number of DIP joints with bony enlargement, pain on pressure and malalignment was positively associated with hand OA. Positive associations with hand OA were also found for these clinical features in the PIP joints (except pain on pressure) and thumb base joints.

Pain on pressure and soft tissue swelling in the MCP joints and pain on palpation of the wrist(s) were negatively associated with hand OA (table 4). No associations with hand $\mathrm{OA}$ were found for pain on palpation of other joints, presence of dactylitis or tenosynovitis (data not shown).

\section{Radiographic and laboratory features}

Radiographic OA features in the DIP joints could better discriminate hand $\mathrm{OA}$ and controls than $\mathrm{OA}$ features in PIP and CMC1 joints (table 5). Osteophytes in the STT joints were not associated with hand OA and showed no discriminatory capability (data not shown). For JSN in the STT joints, the strength of association was slightly weaker $(\mathrm{OR}=1.75,95 \%$ CI 1.16 to 2.65$)$ than for JSN in the CMC1 joints, whereas the AUC value was similar (0.62,
Table 2 Diseases and conditions ${ }^{*}$ that were possible or definite causes of hand complaints in the control group $(n=70)$ in ranked order from most to least prevalent

\section{Cause of complaints, $\mathrm{n}(\%) \dagger$}

Rheumatoid arthritis $26(37.1)$

Other inflammatory rheumatic diseaseł

Fibromyalgia $17(24.3)$

Psoriatic arthritis $13(18.6)$

Tenosynovitis/trigger finger 9 (12.9)

Other causes $\S \quad 6$ (8.6)

Repetitive strain injury

Hemochromatosis

$3(4.3)$

Vitamin D deficiency

$3(4.3)$

Ganglion

$2(2.9)$

Gout $2(2.9)$

Pseudogout

$1(1.4)$

deQuervain's

$1(1.4)$

Diabetes

$1(1.4)$

Dupuytren's contracture

$1(1.4)$

*The list of 16 prespecified diseases and conditions were given to the treating physician, who marked the relevant disease(s) and condition(s) for each patient.

†Several persons had more than one cause of hand complaints, and the total percentage in the column is therefore exceeding 100. fUnspecified arthritis or unknown $(n=10)$, scleroderma $(n=3)$, systemic lupus erythematosus $(n=2)$, palindromic rheumatoid arthritis $(n=1)$, spondyloarthritis $(n=1)$.

§Unknown $(n=4)$, hypermobility $(n=1)$, erysipelas $(n=1)$.

95\% CI 0.53 to 0.70$)$. However, among patients with JSN in STT joint(s), the majority also demonstrated JSN in CMC1 joint(s) (47/67, 70.1\%).

Marginal erosions in the wrist(s), elevated CRP, ESR, anti-CCP and RF were negatively associated with hand OA (table 5).

\section{DISCUSSION}

In the current multi-centre study, we examined different self-reported, clinical, radiographic and laboratory features and their associations with hand OA and discriminatory abilities, as a first step in the development of new classification criteria for hand, finger and thumb base OA.

Female sex and higher age were associated with hand $\mathrm{OA},{ }^{10}$ which is in line with previous population-based studies, showing a higher prevalence of hand $\mathrm{OA}$ in women, and an increasing prevalence with higher age, especially after the age of 50 years. ${ }^{8}$ Other RMDs such as RA and fibromyalgia, which were common among our controls, also predominantly affect women. ${ }^{11}{ }^{12}$ This is reflected in our results showing that female sex could not discriminate between hand OA and controls. Our hand OA group was almost 10 years older than our controls, 
Table 3 Demographic/clinical variables and self-reported symptoms and their association with hand OA and discriminatory capacity

\begin{tabular}{|c|c|c|}
\hline OR $(95 \% \mathrm{Cl})$ & $\begin{array}{l}\text { AUC }(95 \% \\
\mathrm{Cl})^{\star}\end{array}$ & \\
\hline Female sex & $\begin{array}{l}2.42 \\
(1.12-5.20)\end{array}$ & $\begin{array}{l}0.56 \\
(0.48-0.65)\end{array}$ \\
\hline Age, per 5 years & $\begin{array}{l}1.33 \\
(1.17-1.52)\end{array}$ & $\begin{array}{l}0.70 \\
(0.63-0.78)\end{array}$ \\
\hline Body mass index, per 5 units & $\begin{array}{l}0.87 \\
(0.64-1.20)\end{array}$ & $\begin{array}{l}0.54 \\
(0.45-0.62)\end{array}$ \\
\hline \multicolumn{3}{|l|}{ Family history: } \\
\hline $\mathrm{OA}$ in first-degree relatives & $\begin{array}{l}6.29 \\
(3.15-12.59)\end{array}$ & $\begin{array}{l}0.71 \\
(0.62-0.79)\end{array}$ \\
\hline $\begin{array}{l}\text { Bony swelling in first-degree } \\
\text { relatives }\end{array}$ & $\begin{array}{l}3.53 \\
(1.82-6.85)\end{array}$ & $\begin{array}{l}0.65 \\
(0.57-0.73)\end{array}$ \\
\hline Current or past psoriasis & $\begin{array}{l}0.45 \\
(0.15-1.29)\end{array}$ & $\begin{array}{l}0.53 \\
(0.44-0.62)\end{array}$ \\
\hline $\begin{array}{l}\text { Symptoms in fingers longer } \\
\text { than } 6 \text { months }\end{array}$ & $\begin{array}{l}6.65 \\
(1.34-33.01)\end{array}$ & $\begin{array}{l}0.54 \\
(0.46-0.63)\end{array}$ \\
\hline \multicolumn{3}{|c|}{ Duration of morning stiffness, per 15 min: } \\
\hline Finger joints & $\begin{array}{l}0.97 \\
(0.93-1.00)\end{array}$ & $\begin{array}{l}0.62 \\
(0.53-0.70)\end{array}$ \\
\hline Thumb base joints & $\begin{array}{l}0.95 \\
(0.89-1.01)\end{array}$ & $\begin{array}{l}0.51 \\
(0.43-0.60)\end{array}$ \\
\hline Hand numbness & $\begin{array}{l}0.59 \\
(0.33-1.07)\end{array}$ & $\begin{array}{l}0.56 \\
(0.48-0.65)\end{array}$ \\
\hline \multicolumn{3}{|c|}{ Number of painful joints on most days the previous 6 weeks: } \\
\hline$D$ DIP joints & $\begin{array}{l}1.22 \\
(1.07-1.40)\end{array}$ & $\begin{array}{l}0.67 \\
(0.59-0.75)\end{array}$ \\
\hline$>$ PIP joints & $\begin{array}{l}0.98 \\
(0.90-1.07)\end{array}$ & $\begin{array}{l}0.52 \\
(0.43-0.61)\end{array}$ \\
\hline$\checkmark \mathrm{MCP}$ joints & $\begin{array}{l}0.82 \\
(0.73-0.93)\end{array}$ & $\begin{array}{l}0.63 \\
(0.55-0.72)\end{array}$ \\
\hline Thumb base joints & $\begin{array}{l}1.12 \\
(0.79-1.58)\end{array}$ & $\begin{array}{l}0.53 \\
(0.44-0.61)\end{array}$ \\
\hline \multicolumn{3}{|c|}{ Painful joints on most days the previous 6 weeks: } \\
\hline Elbow(s) & $\begin{array}{l}0.40 \\
(0.20-0.81)\end{array}$ & $\begin{array}{l}0.58 \\
(0.49-0.66)\end{array}$ \\
\hline Wrist(s) & $\begin{array}{l}0.29 \\
(0.16-0.54)\end{array}$ & $\begin{array}{l}0.64 \\
(0.56-0.72)\end{array}$ \\
\hline$>$ Toes & $\begin{array}{l}0.52 \\
(0.28-0.96)\end{array}$ & $\begin{array}{l}0.57 \\
(0.49-0.66)\end{array}$ \\
\hline
\end{tabular}

*Interpretation of AUC values: $0.50-0.59=$ no discrimination, $0.60-0.69=$ poor discrimination, $0.70-0.79=$ acceptable dis crimination, and $\geq 0.80$ = excellent discrimination. AUC, area under receiver operating curves; DIP, distal interphalangeal; MCP, metacarpophalangeal; OA, osteoarthritis; PIP, proximal interphalangeal.

and increasing age showed acceptable discrimination between groups. Whereas the ACR criteria for hand OA do not include points for either female sex or higher age, ${ }^{1}$ the ACR criteria for both knee and hip OA include a criterion of age above 50 years. ${ }^{13} 14$

Family history of OA was one of the few self-reported items with acceptable discrimination between the groups.
Table 4 Clinical examination features and their association with hand $\mathrm{OA}$ and discriminatory capacity

\section{OR $(95 \% \mathrm{Cl})$ \\ AUC (95\% Cl)*}

Number of joints with bony enlargement:

$\begin{array}{lll}\text { - DIP joints } & 1.33 & 0.71 \\ & (1.18-1.51) & (0.64-0.78) \\ \text { - PIP joints } & 1.22 & 0.64 \\ & (1.08-1.38) & (0.56-0.72) \\ \text { - MCP joints } & 1.02 & 0.51 \\ & (0.71-1.48) & (0.42-0.59) \\ \text { - Thumb base joints } & 1.96 & 0.59 \\ & (1.20-3.19) & (0.51-0.67)\end{array}$

Number of joints with pain on pressure:

\begin{tabular}{|c|c|c|c|}
\hline 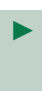 & DIP joints & $\begin{array}{l}1.24 \\
(1.08-1.43)\end{array}$ & $\begin{array}{l}0.64 \\
(0.56-0.72)\end{array}$ \\
\hline$\nabla$ & PIP joints & $\begin{array}{l}1.02 \\
(0.92-1.12)\end{array}$ & $\begin{array}{l}0.53 \\
(0.44-0.61)\end{array}$ \\
\hline$\triangleright$ & MCP joints & $\begin{array}{l}0.81 \\
(0.71-0.93)\end{array}$ & $\begin{array}{l}0.62 \\
(0.54-0.70)\end{array}$ \\
\hline$\triangleright$ & Thumb base joints & $\begin{array}{l}1.51 \\
(1.03-2.22)\end{array}$ & $\begin{array}{l}0.59 \\
(0.50-0.67)\end{array}$ \\
\hline \multicolumn{4}{|c|}{ Number of joints with soft tissue swelling: } \\
\hline$\triangleright$ & DIP joints & $\begin{array}{l}1.17 \\
(0.91-1.52)\end{array}$ & $\begin{array}{l}0.55 \\
(0.47-0.63)\end{array}$ \\
\hline 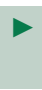 & PIP joints & $\begin{array}{l}1.00 \\
(0.86-1.17)\end{array}$ & $\begin{array}{l}0.53 \\
(0.45-0.61)\end{array}$ \\
\hline$\triangleright$ & MCP joints & $\begin{array}{l}0.48 \\
(0.32-0.73)\end{array}$ & $\begin{array}{l}0.66 \\
(0.57-0.74)\end{array}$ \\
\hline$\triangleright$ & Thumb base joints & $\begin{array}{l}0.83 \\
(0.32-2.16)\end{array}$ & $\begin{array}{l}0.51 \\
(0.42-0.59)\end{array}$ \\
\hline
\end{tabular}

Number of joints with malalignment:

\begin{tabular}{lll} 
D DIP joints & 4.09 & 0.68 \\
& $(1.88-8.87)$ & $(0.60-0.75)$ \\
D PIP joints & 1.75 & 0.57 \\
& $(1.01-3.04)$ & $(0.48-0.65)$ \\
D Thumb base joints & 3.28 & 0.55 \\
& $(1.00-10.72)$ & $(0.47-0.63)$ \\
Pain on palpation in & 0.42 & 0.58 \\
wrist(s) & $(0.22-0.82)$ & $(0.50-0.67)$ \\
\hline
\end{tabular}

*Interpretation of AUC values: $0.50-0.59=$ no discrimination, $0.60-0.69=$ poor discrimination, $0.70-0.79=$ acceptable discrimi nation, and $\geq 0.80=$ excellent discrimination.

AUC, area under receiver operating curves; DIP, distal interphalangeal; MCP, metacarpophalangeal; OA, osteoarthritis; PIP, proximal interphalangeal.

In addition to age and female sex, hereditary factors are well-known risk factors for hand OA. ${ }^{15}$ Several candidate genes have been identified, each leading to small increases in the risk of hand OA. ${ }^{16}$

The observed association between symptom duration and hand $\mathrm{OA}$ reflects the chronicity of hand $\mathrm{OA}$ as a disease. Nevertheless, the majority of both patients with hand $\mathrm{OA}$ and controls had experienced symptoms for more than 6 months, as reflected by the low AUC value. Self-reported pain and pain on pressure in DIP joints were positively associated with hand $\mathrm{OA}$, and 
Table 5 Radiographic and laboratory features and their association with hand $\mathrm{OA}$ and discriminatory capacity

\begin{tabular}{lll}
\hline OR $(\mathbf{9 5 \%} \mathbf{~ C l})$ & \multicolumn{2}{c}{ AUC $(\mathbf{9 5 \%} \mathbf{~ C l})^{*}$} \\
\hline Number of joints with radiographic osteophytes: \\
\hline DIP joints & 1.62 & 0.82 \\
& $(1.40-1.88)$ & $(0.76-0.88)$ \\
D PIP joints & 1.45 & 0.78 \\
& $(1.27-1.67)$ & $(0.71-0.85)$ \\
- MCP joints & 1.22 & 0.58 \\
& $(0.91-1.63)$ & $(0.49-0.66)$ \\
- CMC1 & 2.17 & 0.67 \\
& $(1.47-3.21)$ & $(0.59-0.75)$
\end{tabular}

Number of joints with radiographic joint space narrowing:

\begin{tabular}{|c|c|c|c|}
\hline & DIP joints & $\begin{array}{l}1.57 \\
(1.36-1.82)\end{array}$ & $\begin{array}{l}0.82 \\
(0.76-0.89)\end{array}$ \\
\hline 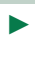 & PIP joints & $\begin{array}{l}1.45 \\
(1.24-1.69)\end{array}$ & $\begin{array}{l}0.77 \\
(0.70-0.84)\end{array}$ \\
\hline$>$ & MCP joints & $\begin{array}{l}0.98 \\
(0.80-1.20)\end{array}$ & $\begin{array}{l}0.51 \\
(0.42-0.60)\end{array}$ \\
\hline & CMC1 & $\begin{array}{l}1.94 \\
(1.29-2.91)\end{array}$ & $\begin{array}{l}0.63 \\
(0.55-0.71)\end{array}$ \\
\hline \multicolumn{4}{|c|}{ Number of joints with radiographic central erosions: } \\
\hline 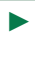 & DIP joints & $\begin{array}{l}2.90 \\
(1.67-5.04)\end{array}$ & $\begin{array}{l}0.72 \\
(0.65-0.80)\end{array}$ \\
\hline & PIP joints & $\begin{array}{l}1.52 \\
(1.04-2.21)\end{array}$ & $\begin{array}{l}0.58 \\
(0.50-0.67)\end{array}$ \\
\hline
\end{tabular}

Number of joints with radiographic marginal erosions:

\begin{tabular}{|c|c|c|c|}
\hline$\triangleright$ & PIP joints & $\begin{array}{l}0.96 \\
(0.57-1.63)\end{array}$ & $\begin{array}{l}0.53 \\
(0.44-0.61)\end{array}$ \\
\hline$\triangleright$ & MCP joints & $\begin{array}{l}0.57 \\
(0.27-1.21)\end{array}$ & $\begin{array}{l}0.52 \\
(0.43-0.61)\end{array}$ \\
\hline$\triangleright$ & Wrist bones & $\begin{array}{l}0.53 \\
(0.29-0.98)\end{array}$ & $\begin{array}{l}0.56 \\
(0.47-0.65)\end{array}$ \\
\hline \multicolumn{4}{|c|}{ Laboratory tests: } \\
\hline$\triangleright$ & Elevated CRP $\geq 5 \mathrm{mg} / \mathrm{L}$ & $\begin{array}{l}0.45 \\
(0.24-0.85)\end{array}$ & $\begin{array}{l}0.59 \\
(0.50-0.67)\end{array}$ \\
\hline$\triangleright$ & Elevated ESR $\geq 15 \mathrm{~mm} /$ hour & $\begin{array}{l}0.39 \\
(0.20-0.75)\end{array}$ & $\begin{array}{l}0.61 \\
(0.52-0.70)\end{array}$ \\
\hline$\triangleright$ & $\begin{array}{l}\text { Positive anti-cyclic } \\
\text { citrullinated protein }\end{array}$ & $\begin{array}{l}0.13 \\
(0.04-0.50)\end{array}$ & $\begin{array}{l}0.62 \\
(0.51-0.72)\end{array}$ \\
\hline$\triangleright$ & Positive rheumatoid factor & $\begin{array}{l}0.35 \\
(0.14-0.87)\end{array}$ & $\begin{array}{l}0.59 \\
(0.49-0.70)\end{array}$ \\
\hline
\end{tabular}

*Interpretation of AUC values: $0.50-0.59=$ no discrimination, 0.60-0.69 = poor discrimination, $0.70-0.79=$ acceptable discrimination, and $\geq 0.80$ = excellent discrimination.

AUC, area under receiver operating curves; CMC1, first carpometacarpal; CRP, Creactive protein; DIP, distal interphalangeal; ESR, erythrocyte sedimentation rate; MCP; metacarpophalangeal; OA, osteoarthritis; PIP, proximal interphalangeal.

positive associations were also observed for pain on pressure in thumb base joints. The involvement of PIP joints also in other diseases such as RA led to no significant associations with hand $\mathrm{OA}$ for pain in this joint group and no discrimination. Due to rather high frequency of RA and other inflammatory RMDs among our controls, pain, stiffness and soft tissue swelling in MCP joints and a long duration of morning stiffness were negatively associated with hand OA. In line with these results, the current ACR criteria for hand OA give 1 point to persons with fewer than three swollen MCP joints, ${ }^{1}$ whereas the ACR criteria for knee OA give 1 point to persons with morning stiffness less than 30 min. ${ }^{14}$

Although radiographs are not needed for the diagnosis of hand OA, unless there is doubt about the clinical diagnosis, ${ }^{3}$ conventional radiographs may be useful in research settings for classification of hand OA. In general, the radiographic features showed better discrimination than the clinical features. Indeed, the number of DIP joints with osteophytes and JSN were the only features with excellent discrimination. In addition to positive associations observed for all radiographic features in the DIP joints and hand OA, associations were also found for radiographic features in the PIP joints and thumb base joints. The weaker associations and lower AUC values, especially in thumb base joints, can be explained by lower OA prevalent in this joint group in our study population leading to lower sensitivity and thus lower AUC values. No statistically significant association and no discrimination was observed for radiographic features in the MCP joints, due to lower prevalence of $\mathrm{OA}$ in this joint group. Whereas the hand radiographs were read centrally by two experienced readers and a third adjudicator if needed, the clinical examination was performed locally at each center without specific training or reliability testing. Hence, poorer reliability of the clinical examination may potentially have affected the results.

No imaging modalities other than radiographs were included in our data collection. Ultrasound may be more sensitive to detect osteophytes than radiographs and clinical examination. ${ }^{17}$ However, due to more limited data on the validity of ultrasound, radiographs are currently the recommended outcome measure for evaluation of structural hand OA pathologies. ${ }^{18}$ Further, most large population-based OA studies have obtained hand radiographs of their participants and have not used ultrasound. ${ }^{8}{ }^{19}{ }^{20}$ MRI is not feasible in large studies due to high costs. Studies of knees have suggested that MRI findings of $\mathrm{OA}$ are so common as to not distinguish well between those with OA and those without it, ${ }^{21}$ and we suspect the same is true for hand OA.

In contrast to inflammatory RMDs, OA is less often associated with systemic inflammation. Both elevated ESR and CRP were negatively associated with hand OA with similar ability to discriminate between persons with hand OA and controls. Although ESR is often criticised for being dependent on age, sex, weight and comorbidities, the ACR clinical and laboratory criteria for knee OA and the ACR criteria for hip OA include ESR using cutoffs of less than 45 and less than $20 \mathrm{~mm} /$ hour, respectively. ${ }^{13}{ }^{14}$ As expected, we found negative associations with hand OA for anti-CCP and RF. The extra costs and the invasive nature of blood tests raise questions about the usefulness of including laboratory markers in new classification criteria for hand OA. Biomarkers of 
bone or cartilage may ultimately prove useful in classifying hand OA, but would not be feasible currently.

The advantage of the current data collection is the broad range of hand OA symptoms and disease severity due to inclusion of patients from both primary and secondary/tertiary care from multiple countries in two continents. With the inclusion of persons with noninflammatory conditions among our controls, we believe that our future criteria will be more useful in populationbased studies, where non-inflammatory RMDs predominate as causes of hand complaints rather than systemic inflammatory RMDs. Our study population had a diverse range of conditions in contrast to the control population that was used in the development of the ACR criteria for hand OA where all controls, except two $(2.0 \%)$, had an inflammatory joint disease. ${ }^{1}$ Psoriatic arthritis is an important differential diagnosis that might be difficult to distinguish from hand OA that coexists with psoriasis. Relatively few patients with psoriatic arthritis were included in the control group and several patients with hand $\mathrm{OA}$ had psoriasis, which may explain why psoriasis could not well differentiate between hand OA and controls.

The low AUC values for most features suggest that one single feature is not enough to classify hand OA, but the classification criteria should include a set of different features. In the next step, an expert panel will agree upon a set of features that will be tested in a decision analytic software (www.1000minds.com), based on the results from the current study and expert opinions. In these exercises, the 1000Minds software will be used to force experts to choose cases more likely to have OA based on diagnostic features (ie, criteria) and then the software will be used to rank the criteria according to their importance. Based on the results from the current study, which is solely data-driven, and the results from the 1000Minds exercises, which are based on expert opinions, our final criteria set will be determined.

Our analyses focus on the associations with hand OA overall. Since the physicians were not asked whether the patients' complaints were due to interphalangeal OA or thumb base OA specifically, we were not able to look at these phenotypes separately. We are aiming for three separate criteria sets, including hand OA overall, interphalangeal $\mathrm{OA}$ and thumb base $\mathrm{OA}$, and the importance of the potential criteria identified in these analyses will, therefore, be studied for the three groups separately in the next steps.

In conclusion, a comparison of patients with hand $\mathrm{OA}$ and controls was performed as a first step in the development of classification criteria for hand, finger and thumb base OA. Patients with hand OA and controls demonstrated differences with regard to symptoms, clinical findings, radiographic changes and laboratory tests results with best discrimination observed for the radiographic features. Additional exercises to determine the weight of the different features are needed before the new classification criteria for hand OA can be launched.

\section{Author affiliations}

${ }^{1}$ Rheumatology, Diakonhjemmet Hospital, Oslo, Norway

${ }^{2}$ Rheumatology Section, Boston University School of Medicine, Boston,

Massachusetts, USA

${ }^{3}$ Arthritis Research UK Epidemiology Unit and National Institute for Health Research Biomedical Research Centre, The University of Manchester, Manchester, UK

${ }^{4}$ Academic Rheumatology, School of Medicine, University of Nottingham,

Nottingham, UK

${ }^{5}$ Nottingham NIHR-BRC,Nottingham, UK

${ }^{6}$ Department of Rheumatology, Hopital Saint-Antoine,Paris, France

${ }^{7}$ Department of General Practice, Department of Orthopedics, Erasmus Medical

Center, Rotterdam, Netherlands

${ }^{8}$ Frysja Medical Practice, Oslo, Norway

${ }^{9}$ Rheumatology, Universidad Autonoma De Madrid, Madrid, Spain

${ }^{10}$ Rheumatology, Cedars-Sinai Medical Center, Los Angeles, California, USA

${ }^{11}$ Rheumatology, Landspitali, Reykjavik, Iceland

${ }^{12}$ Rheumatology, Leiden University Medical Center, Leiden, Netherlands

${ }^{13}$ Faculty of Medicine Pierre \& Marie Curie Paris VI, Hopital Saint-Antoine,Paris, France

${ }^{14}$ Rheumatology Unit, Department of Medicine-DIMED, University of Padova School of Medicine and Surgery, Padova, Italy

${ }^{15}$ Section for Outcomes Research, Center for Medical Statistics, Informatics, and Intelligent Systems, Medical University of Vienna, Wien, Austria

${ }^{16}$ Rheumatology, University Hospital Ghent, Gent, Belgium

Acknowledgements We thank the patients, study nurses and physicians who were involved in the data collection.

Twitter None.

Contributors All coauthors had substantial contributions to the conception or design of the work, or the acquisition, analysis or interpretation of data. IKH drafted the paper, and all coauthors revised it critically for important intellectual content and gave their final approval of the version published.

Funding The project on the development of new classification criteria for hand $O A$ is funded by EULAR. The EULAR executive committee has not been involved in the study design, analyses or interpretation of results.

Competing interests Ida K. Haugen reports a research grant from Pfizer, outside the submitted work. Francis Berenbaum reports personal fees from Boehringer, Bone Therapeutics, Expanscience, Galapagos, Gilead, GSK, Merck Sereno, MSD, Nordic, Novartis, Pfizer, Regulaxis, Roche, Sandoz, Sanofi, Servier, UCB, Peptinov, TRB Chemedica, 4P Pharma, outside the submitted work. Sita Bierma-Zeinstra reports grants from The Netherlands Organisation for Health Research and Development, CZ, European Union, Foreum, Dutch Arthritis Association, personal fees from Infirst healthcare, Pfizer and Osteoarthritis and Cartilage, outside the submitted work. Emmanuel Maheu reports personal fees from Expanscience, Mylan-Meda, TRB Chemedica, Pierre Fabre, Celgène and Fidia, and non-financial support from Pfizer, outside the submitted work. Roberta Ramonda reports honoraria for speaking engagements and for Advisory Board from Abbvie, Celgene, Novartis, Pfizer and Lilly. Tanja Stamm received speaker fees from Sanofi, AbbVie and Roche. Désirée van der Heijde reports personal fees from AbbVie, personal fees from Amgen, personal fees from Astellas, personal fees from AstraZeneca, personal fees from BMS, personal fees from Boehringer Ingelheim, personal fees from Celgene, personal fees from Cyxone, personal fees from Daichii, personal fees from Eisai, personal fees from EllyLilly, personal fees from Galapagos, personal fees from Gilead, personal fees from GSK, personal fees from Janssen, personal fees from Merck, personal fees from Novartis, personal fees from Pfizer, personal fees from Regeneron, personal fees from Roche, personal fees from Sanofi, personal fees from Takeda, personal fees from UCB Pharma, outside the submitted work; and Director Imaging Rheumatology BV. Ruth Wittoek reports personal fees from Abbvie, personal fees from Galapagos, personal fees from UCB, personal fees from Bristol Myers Squib, personal fees from Tilman, grants from Amgen, outside the submitted work. Margreet Kloppenburg reports grants from European League Against Rheumatism during the conduct of the study, fee for consultancy (Abbvie, Pfizer, Levicept, GlaxoSmithKline, Merck-Serono, Kiniksa, Flexion) and local investigator of industry-driven trial (Abbvie), other from Dutch Society of Rheumatology, Wolters Kluwer (UptoDate) and Springer Verlag (Reumatologie en klinische immunologie), grants from Pfizer, outside the submitted work. David Felson, Abhishek Abhishek, Tove Borgen, Gabriel Herrero-Beaumont, Mariko L. Ishimori, Helgi Jonsson, Féline P.B. Kroon, Valentin Ritschl, Elsie Greibrokk and Wilma Smeets have no conflicts of interest. 
Patient consent for publication Consent obtained directly from patient(s). Data sharing statement Data are available upon reasonable request.

Provenance and peer review Not commissioned; externally peer reviewed.

Open access This is an open access article distributed in accordance with the Creative Commons Attribution Non Commercial (CC BY-NC 4.0) license, which permits others to distribute, remix, adapt, build upon this work non-commercially, and license their derivative works on different terms, provided the original work is properly cited, appropriate credit is given, any changes made indicated, and the use is non-commercial. See: http://creativecommons.org/licenses/by-nc/4.0/.

\section{ORCID iDs}

Ida K Haugen http://orcid.org/0000-0001-7810-2216

David T Felson http://orcid.org/0000-0002-2668-2447

Féline PB Kroon http://orcid.org/0000-0002-8940-0582

Tanja A Stamm http://orcid.org/0000-0003-3073-7284

Desirée van der Heijde http://orcid.org/0000-0002-5781-158X

\section{REFERENCES}

1 Altman R, Alarcón G, Appelrouth D, et al. The American College of Rheumatology criteria for the classification and reporting of osteoarthritis of the hand. Arthritis Rheum 1990;33:1601-10.

2 Mahendira D, Towheed TE. Systematic review of non-surgical therapies for osteoarthritis of the hand: an update. Osteoarthritis Cartilage 2009;17:1263-8.

3 Zhang W, Doherty M, Leeb BF, et al. EULAR evidence-based recommendations for the diagnosis of hand osteoarthritis: report of a task force of ESCISIT. Ann Rheum Dis 2009;68:8-17.

4 Felson DT, Anderson JJ. Methodological and statistical approaches to criteria development in rheumatic diseases. Baillieres Clin Rheumatol 1995;9:253-66.

5 Bellamy N, Campbell J, Haraoui B, et al. Dimensionality and clinical importance of pain and disability in hand osteoarthritis: development of the Australian/Canadian (AUSCAN) osteoarthritis hand index. Osteoarthritis Cartilage 2002;10:855-62.

6 Dreiser RL, Maheu E, Guillou GB, et al. Validation of an algofunctional index for osteoarthritis of the hand. Rev Rhum Engl Ed 1995;62:43S-53S.

7 Kloppenburg M, Peterfy C, Haugen IK, et al. Phase Ila, placebo-controlled, randomised study of lutikizumab, an anti-interleukin-1alpha and anti-interleukin-1beta dual variable domain immunoglobulin, in patients with erosive hand osteoarthritis. Ann Rheum Dis 2019;78:413-20.

8 Haugen IK, Englund M, Aliabadi $\mathrm{P}$, et al. Prevalence, incidence and progression of hand osteoarthritis in the general population: the framingham osteoarthritis study. Ann Rheum Dis 2011;70:1581-6.

9 Altman RD, Gold GE. Atlas of individual radiographic features in osteoarthritis, revised. Osteoarthritis Cartilage 2007;15:A1-56.

10 van der Heijde DM, van Leeuwen MA, van Riel PL, et al. Biannual radiographic assessments of hands and feet in a three-year prospective followup of patients with early rheumatoid arthritis. Arthritis Rheum 1992;35:26-34.

11 Ngo ST, Steyn FJ, McCombe PA. Gender differences in autoimmune disease. Front Neuroendocrinol 2014;35:347-69.

12 Vincent A, Lahr BD, Wolfe F, et al. Prevalence of fibromyalgia: a population-based study in olmsted county, minnesota, utilizing the rochester epidemiology project. Arthritis Care Res (Hoboken) 2013;65:786-92.

13 Altman R, Alarcón G, Appelrouth D, et al. The American College of Rheumatology criteria for the classification and reporting of osteoarthritis of the hip. Arthritis Rheum 1991;34:505-14.

14 Altman R, Asch E, Bloch D, et al. Development of criteria for the classification and reporting of osteoarthritis. Classification of osteoarthritis of the knee. Diagnostic and Therapeutic Criteria Committee of the American Rheumatism Association. Arthritis Rheum 1986;29:1039-49.

15 Ishimori ML, Altman RD, Cohen MJ, et al. Heritability patterns in hand osteoarthritis: the role of osteophytes. Arthritis Res Ther 2010;12:R180.

16 Marshall M, Watt FE, Vincent TL, et al. Hand osteoarthritis: clinical phenotypes, molecular mechanisms and disease management. Nat Rev Rheumatol 2018;14:641-56.

17 Mathiessen A, Haugen IK, Slatkowsky-Christensen B, et al. Ultrasonographic assessment of osteophytes in 127 patients with hand osteoarthritis: exploring reliability and associations with MRI, radiographs and clinical joint findings. Ann Rheum Dis 2013;72:516.

18 Kloppenburg M, Bøyesen P, Visser AW, et al. Report from the OMERACT hand osteoarthritis working group: set of core domains and preliminary set of instruments for use in clinical trials and observational studies. J Rheumatol 2015;42:2190-7.

19 Schaefer LF, McAlindon TE, Eaton CB, et al. The associations between radiographic hand osteoarthritis definitions and hand pain: data from the osteoarthritis initiative. Rheumatol Int 2018;38:403-13.

20 Dahaghin S, SMA B-Z, Ginai AZ, et al. Prevalence and pattern of radiographic hand osteoarthritis and association with pain and disability (the Rotterdam study). Ann Rheum Dis 2005;64:682-7.

21 Guermazi A, Niu J, Hayashi D, et al. Prevalence of abnormalities in knees detected by MRI in adults without knee osteoarthritis: population based observational study (Framingham Osteoarthritis Study). BMJ 2012;345:e5339. 